\title{
User-Centered Development of a Public Transportation Vehicle Operated in a Demand Responsive Environment
}

\author{
Alexander Mueller ${ }^{1}$, Stefanie Beyer ${ }^{1}$, Gerhard Kopp², Oliver Deisser ${ }^{2}$ \\ ${ }^{1}$ Hochschule Esslingen, University of Applied Sciences, \\ Faculty of Automotive Engineering, Kanalstraße 33, \\ 73728 Esslingen, Germany \\ \{Alexander.Mueller, Stefanie.Beyer\}@hs-esslingen.de \\ ${ }^{2}$ German Aerospace Center, Institute of Vehicle Concepts, \\ Pfaffenwaldring 38-40, \\ 70569 Stuttgart, Germany \\ \{Gerhard.Kopp, Oliver.Deisser\}@dlr.de
}

\begin{abstract}
Within the scope of the research project "Reallabor Schorndorf", funded by the German state, demand responsive transport and operating systems as well as a virtual vehicle concept for public transport (PT) were designed and tested in a "real-world laboratory". The aim of the subproject Vehicle Development was to design a vehicle in an effective and repeatable manner that best meets the users requirements with respect to the demand responsive public transport system. The novel user-centered development methodology and the exemplary result are highlighted in this contribution.
\end{abstract}

Keywords: Overall vehicle design · User-centered vehicle development $\cdot$ Vehicle ergonomics - Barrier-free accessibility - Passenger behavior - User groups · Personas · RAMSIS ${ }^{\circledR} \cdot$ User-scenarios · Dimensional layout conception · public transport

\section{Introduction}

\subsection{Current Situation and Problem}

The high share of individual transport in urban areas with a congested road network is directly related to the overall traffic volume and reflects the unattractiveness of PT services in and around metropolitan areas. One of the reasons behind this traffic situation can be seen in the regular PT service, designed for high passenger numbers, that often cause long travel times due to inefficient route guidance, leading to overcrowding at peak hours along with a low clock - frequency. Additionally, the currently used design standard for public transport vehicles mainly focuses on key performance indicators such as maximum occupancy, seat spacing and aisle widths. As a result, individual human body - dimensions, motoric capabilities and the luggage carried by occupants are only taken into account indirectly. This shows that the considerations of PT users are currently not sufficiently represented within the definition of the PT operating system and the design of PT vehicles. Emphasis has to be given to 
this situation by the fact that PT vehicles will operate autonomously in the future and that bus driver assistance for, as an example, wheelchair users getting on or off the bus, will be eliminated.

\subsection{Method of Resolution}

The main goal of the study was to adapt vehicles used in a demand responsive PT environment to the needs of particular users. For this purpose, not only critical body dimensions but also user groups (personas) and their luggage were defined and mapped digitally in the concept phase for layout and evaluation purposes. By means of the digital man-model software RAMSIS $®$, the geometrical representations of six personas (e.g. wheelchair user, person with stroller) with respective limitations were modeled. In a further step, the modelled personas were combined to fictional scenarios of typical user situations (e.g. maximum occupancy or maximum utilization of multi-use space with strollers and/or walkers). In order to evaluate the defined fictional user-scenarios, the number of passengers and the type and amount of carried luggage in the demand responsive transport system were tracked on several days over a span of four weeks.

\subsection{Research Project "Reallabor Schorndorf"}

Since the beginning of 2015, novel models for the interaction between of science and society, termed as "real-world laboratories" (Reallabor), are being funded by the Ministry of Science, Research and Art of the State of the German State of BadenWürttemberg with a total sum of 15 million Euros. One of the projects receiving funding is the program is the research Project "Reallabor Schorndorf", with a budget of around 1.2 million Euros between February 2016 and January 2019 [1].

The research project consisted of various subprojects. In terms of content, the operating concept for the organization of the demand-responsive public transport system as well as the vehicle concept were developed in separate subprojects, the latter taking into account the modified requirements as described in the novel operationg concept. Furthermore, the project benefitted in particular from the fact that the subproject "Citizen Participation" handled the dialogue with citizens and the coordination between citizens together with the municipality.

\section{Basic Analysis}

In order to fulfill a goal-oriented overall vehicle design, basic analyses were carried out in the fields of demand responsive public transport systems, user-centered vehicle design and user-centered interface development.

\subsection{Demand Responsive Public Transport System}

Demand responsive public transport refers to a public transport system without the regular fixed line traffic. This system is based on user requests and calculates a flexi- 
ble route according to the user's demands. In principle, the idea of organizing public transport according to needs of users is not new. It is known that these systems were introduced in the 1970s, when the computer-controlled system "Rufbus Friedrichshafen" [2] was established and exist till date (e.g. Kutsuplus Helsinki [3]). However, these operating concepts could not break through due to economic concerns $[2,3]$. The demand responsive approach to the organization of public transport requires the use of small and agile vehicles, in which a low number of passengers are transported at the same time. This leads to increased personnel costs in the current operating model, since on an average the sum of all vehicles in use at any given time steered by a employed bus driver is higher.

Changing circumstances such as new developments in the field of individual networking of bus users with smartphones, as well as progress in autonomous driving make a demand responsive public transport service seem expedient in numerous applications of public transport.

\subsection{User-Centered Vehicle Development}

Within the geometric and user-friendly vehicle development, a distinction must be made between the design of public transport vehicles and that of passenger cars used for individual passenger transport.

Conventional public transport vehicles are normally designed for maximum occupancy and seat spacing [4]. In some cases, so-called threshold percentiles of passengers in sitting posture are considered [5]. Seating arrangements as well as the shape of aisles and multi-functional surfaces primarily fulfill approval-specific requirements and are subordinate to the maximum capacity. Today, the human anatomy is not adequately taken into account in PT vehicle development.

In passenger car development, the vehicle interior is designed by means of digital models and the application of threshold percentiles is state of the art [5]. When planning passenger cars at present, priority is given to the space-saving overall occupant packaging. An ergonomic and the occupants' behavior considering seating arrangement is not fully recognizable. Generally, technical and space-related necessities are given priority.

In order to enhance the value of public transport and to increase its attractiveness, vehicles used in demand-oriented public transport systems must be designed in a userfriendly manner, taking into account the anthropometric and behavioral characteristics of different users.

\subsection{User-Centered Interface Development}

The user-centered interface development respects the user's behavior that bases on emotions and experiences and is closely linked to individual attitude and the associated process of perception and cognition [6]. In terms of requirements analysis and definition, the so-called Persona Method has been proved successfully. The purpose of the method is to enable developers to make decisions from a customer perspective, focusing on critical user groups [7, 8, 9, 10, 11]. 


\section{User-Centered Development of a Public Transport Vehicle}

The user-centered vehicle design takes into account the standardized and proven approach to methodological product development described in VDI 2221 [12]. Since the focus of this research lies in the conception phase, a development process consisting of two concept stages was defined. After each stage, the concepts were evaluated in terms of accomplished requirements followed by a review of the requirements. In the subsequent embodiment phase the progress that was made in the concept and design phase was proved by means of mock-ups in different scales (Figure 1).

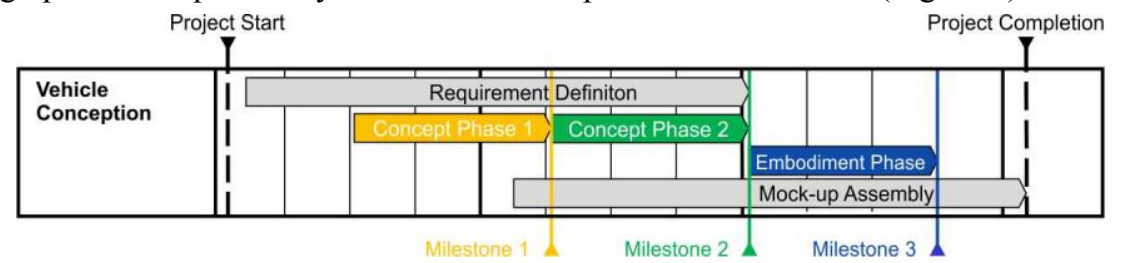

Fig. 1. Systematic vehicle design

\subsection{Requirement Definition}

An autonomous, fully electric, two-axle and low-floor vehicle concept has been developed within the project. The inner-city area of Schorndorf with its established structures was the location of application and operation in inner-city pedestrian shopping zones was considered. As target values, the vehicle speed was defined to lie between 50 and $80 \mathrm{~km} / \mathrm{h}$, with the route having a maximum gradient of $12 \%$.

Since a user-centered design approach was applied, the vehicle length, width and height were derived from the centrifugal und barrier-free development of the interior, including 6 seats and 4 standing spaces along with luggage storage. In this context vehicle users were modelled using the digital man-model RAMSIS $\AA$. Different usage scenarios which result from vehicle operation at different times of the day with different user types who use the vehicle interior in different ways, served for the generation of the virtual interior design. Moreover, for the functional derivation of the main vehicle dimensions, requirements resulting from typical infrastructure were taken into account (e.g. road width, bus stop layout, curb geometry). As an example, a vehicle length of approx. $5 \mathrm{~m}$ combined with a turning circle of max. $12 \mathrm{~m}$ met the requirements.

\subsection{User-Centered Vehicle Conception}

Based on the requirements listed above, the complex vehicle development process was carried out. For operative processing, all requirements were assigned to one of the four subject areas "Complete Vehicle", "Styling", "Security and Accessibility" and "drive and chassis" (see Figure 2).

The subject area "Complete Vehicle" is dedicated to requirements management, user-centered dimensioning including ergonomic design and validation and serves as a basis for generating the package of the main components, the body and the interior and exterior modules. In the area of styling, the aesthetic appearance of the interior 
and exterior was created. Within the area of safety and accessibility, the body structure, including a rudimentary crash structure, and a barrier-free entry and exit system was defined. The basic drive and chassis design is represented by the subject area of the same name and primarily focuses on the rough dimensioning of the battery electric drivetrain and the chassis.
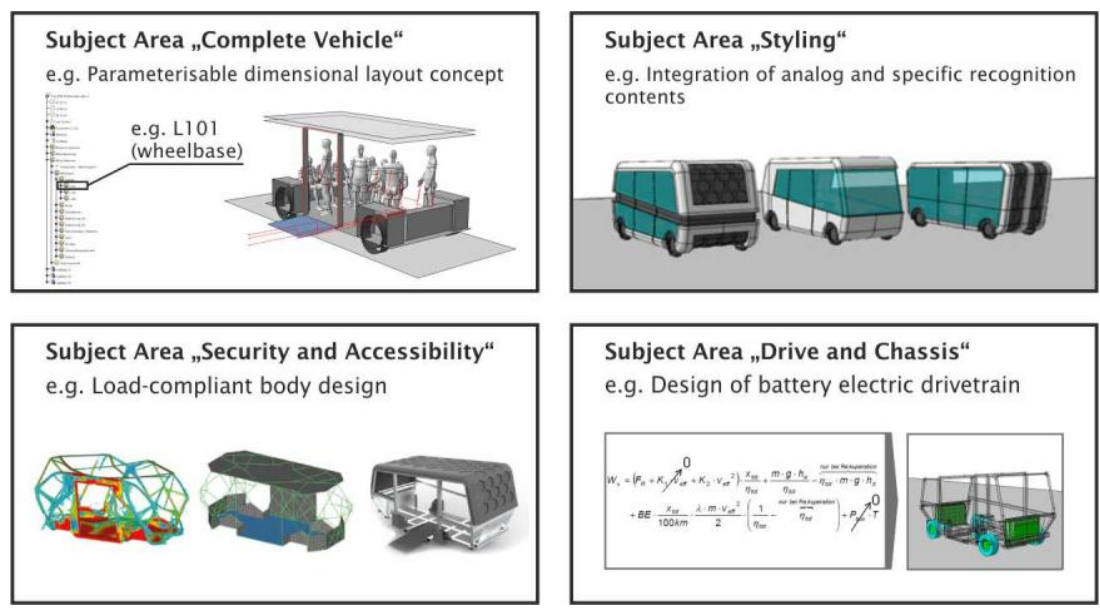

Subject Area "Drive and Chassis“ e.g. Design of battery electric drivetrain

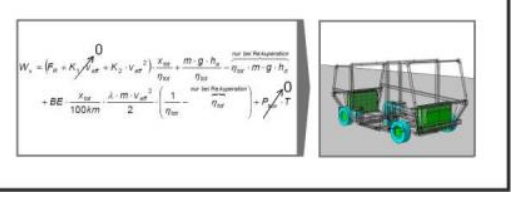

Fig. 2. Subject areas of vehicle development

\section{User-Centered Concept Evaluation with User-Groups}

A key objective of the vehicle conception was the enhancement and application of a user-centered design methodology. The approach chosen in the research project was to extend the Persona method and transfer it to the field of vehicle conception. This results in benefit, since the geometric vehicle design then takes into account not only the anthropometric characteristics of the vehicle users but also the individual psychographic attitude characteristics and the behavior of the users for the first time. The identical user groups (Personas), were also used in the design of the demand-oriented operating concept (app, website, background systems). In this context, properties which were not specific and relevant for modelling but were decisive for the geometric design of the vehicle were first defined and then assigned to the existing personas. As an example in, the definition of the ergonomic key dimension body height, which has no influence on the development of the operating concept was therefore not defined by the subproject "Operating Concept".

\subsection{Persona Definition}

The development of public transport control systems using specific personas that depict public transport users has been proven and tested [9]. Hence four "Schorndorfspecific Personas" were developed together with the citizens of Schorndorf for the operating system in the present research project [13]. These Personas represent typical 
as well as critical public transport users. Pensioners, people with reduced mobility, regular bus users and regular car users were defined as critical target groups. Figure 3 shows an example of the fictitious persona "Ingrid Henke", a 73-year-old pensioner.

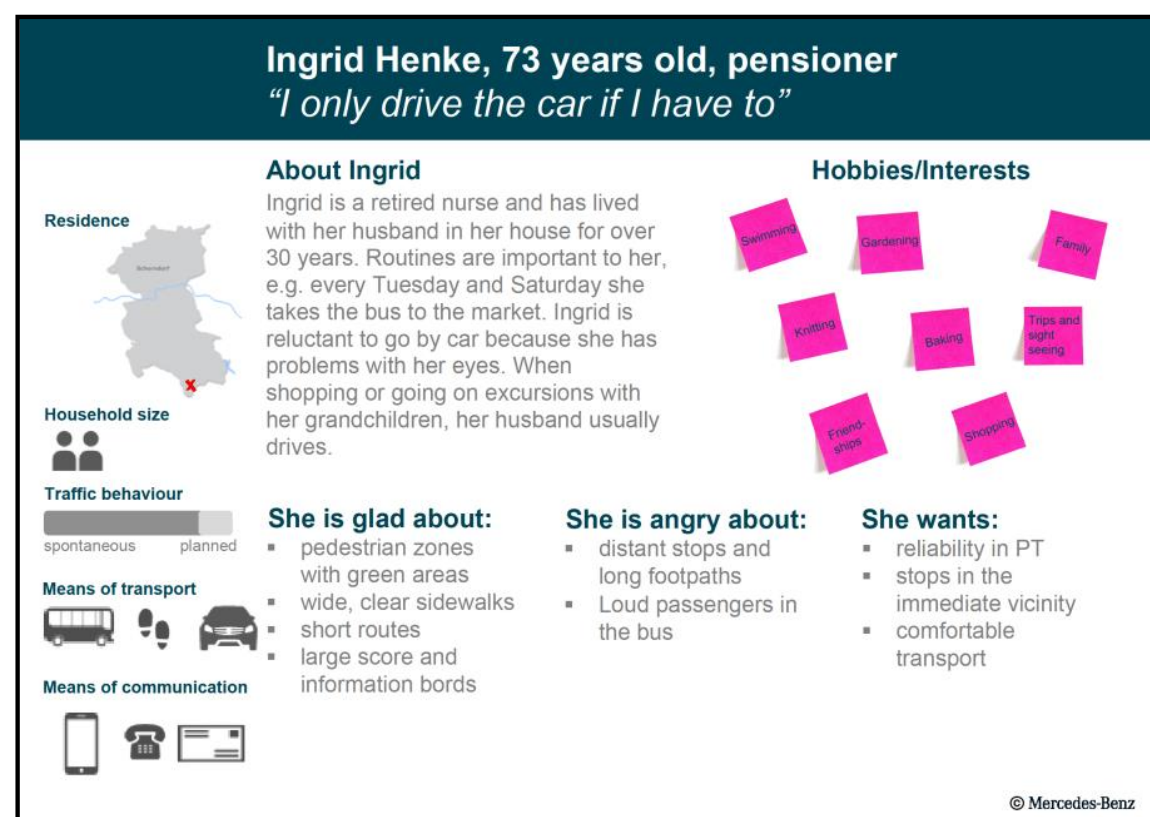

Fig. 3. Persona from the citizen workshop Reallabor Schorndorf [13]

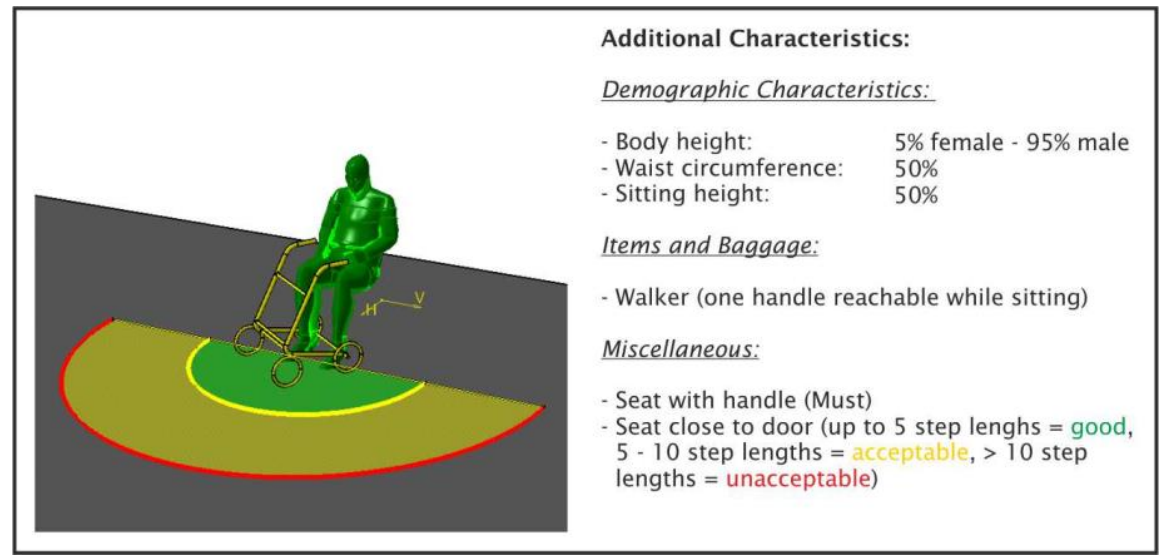

Fig. 4. Physical modelling of the extended persona "pensioner" (Mrs. Ingrid Henke) 


\subsection{User Group Enhancement and Modelling}

As described, the personas defined for the development of the demand-oriented operating system were systematically extended by characteristics that are important for the geometric vehicle design. Essentially, they need to be extended to include demographic characteristics (body geometry), behavioral parameters relating to movement sequences and abilities, and preferred areas of residence as well as psychographic characteristics to assess the shape of the vehicle. This approach resulted in 13 persons modeled with RAMSIS ${ }^{\circledR}$ who could be assigned to different personas having varying attributes such as prams, rollators, wheelchairs and luggage. Figure 4 shows an example of the design-critical pensioner Ingrid Henke physically modelled as a small woman. Essential information required for the clear and consistently reproducible physical modelling is listed in the figure.

\subsection{Derivation of User-Scenarios}

The development of the vehicle interior was based on the physically modelled vehicle users with limiting percentiles, which served as input parameters of the dimensional layout concept. For the first time, the previously defined personas were used to physically model a combination of different user types (user scenarios) in order to geometrically evaluate the interior of local public transport vehicles. Since the user groups defined in this research do not picture all design relevant users, additional personas described in the IP-KOM-ÖV project were implemented [9]. This combination of personas defined four design-critical usage scenarios [14]:

- "Morning", maximum utilization of seats and standing areas; six commuters sitting, four commuters standing.

- "Midmorning", maximum utilization of multi-use space; one persona with stroller standing, two walker users sitting, two personas with luggage sitting.

- "Early-evening", barrier-free accessibility; two walker users sitting, one wheelchair user, two commuters sitting.

- "Late evening", room functionalities and atmosphere; three personas regularly using the car with desire for space sitting, one commuter sitting.

\subsection{Evaluation of User-Scenarios}

In order to evaluate the fictional scenarios, observations were conducted within the real-world laboratory framework of the "Reallabor" project in which a demandresponsive public transportation system was realized [15]. The observations took place on four Saturdays between 7:19 am and 4:19 pm in two different busses and were recorded by a ride-on observer. The passenger capacity utilization was summarized to half-hourly bus cycles. In total 348 passengers and 469 luggage items were recorded. 


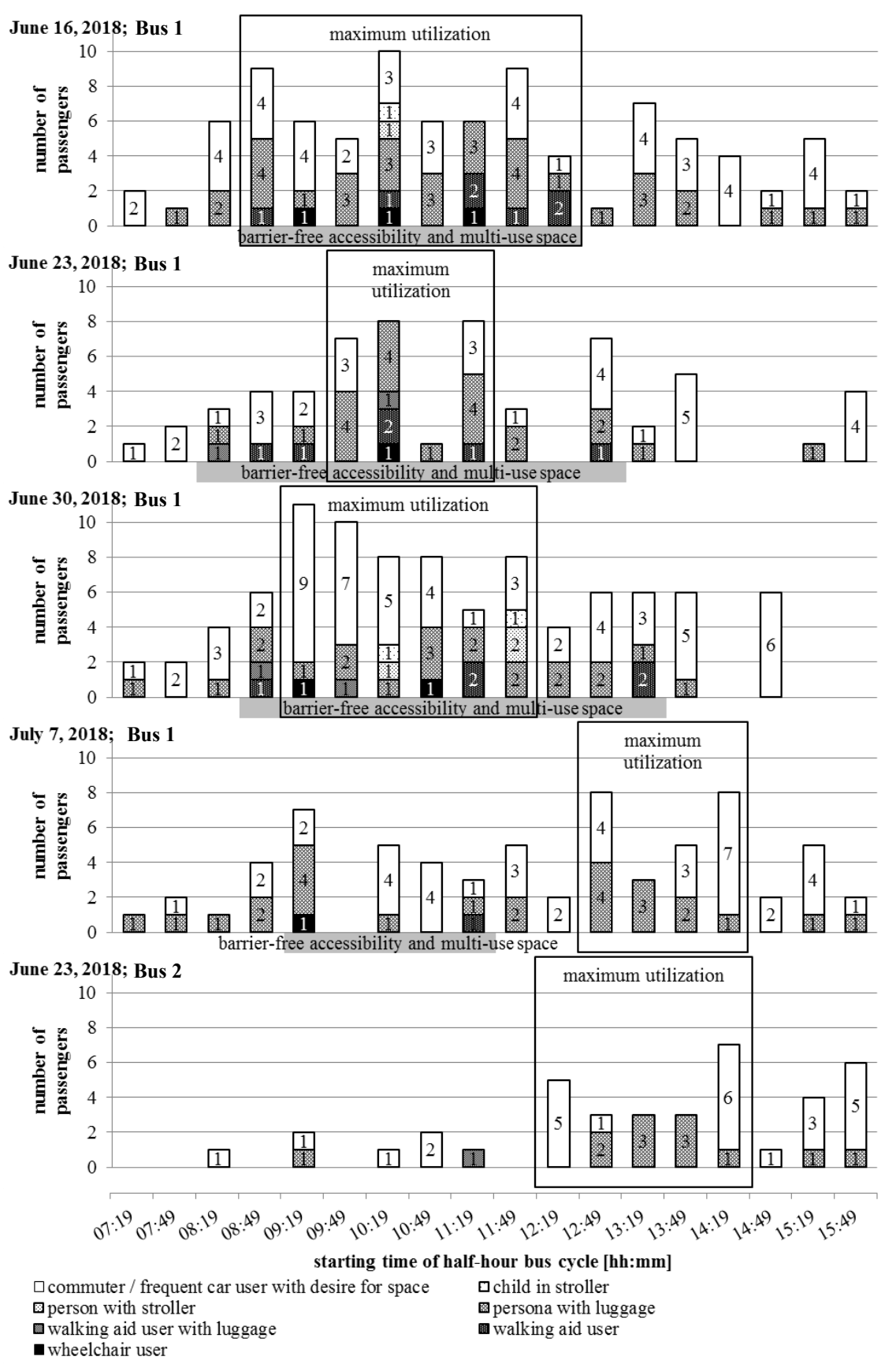

Fig. 5. Distribution over the day of real-life passengers assigned to persona categories and userscenarios [15]. 
The task of relating the observed persons to the defined personas was carried out on basis of information that was identifiable to the observer. This included an estimation of the passengers age, the passengers geometric dimensions, motion capabilities/handicaps, the use of mobility aids and the baggage carried. Accordingly, the passengers were assigned as follows:

- Walking aid user: each person using a walker, crutch(es), or cane(s);

- Commuter/frequent car user with desire for space: each person without luggage, or with irrelevant item(s), and without mobility aid;

- Wheelchair user: each person using a wheelchair;

- Person with luggage: each person with relevant item(s), and without walking aid, or wheelchair;

- Person with stroller: each person with a stroller;

- Person with walking aid and luggage: each person with luggage using crutch(es), or cane(s).

Figure 5 shows the passenger distribution over the day of real-life passengers to persona categories and user-scenarios. The results show, that the presence of the defined scenarios could be confirmed in general, in particular the maximum occupancy was verified. All Scenarios appeared less marked and it was found that multi-use space and barrier-free accessibility was required at maximum occupancy.

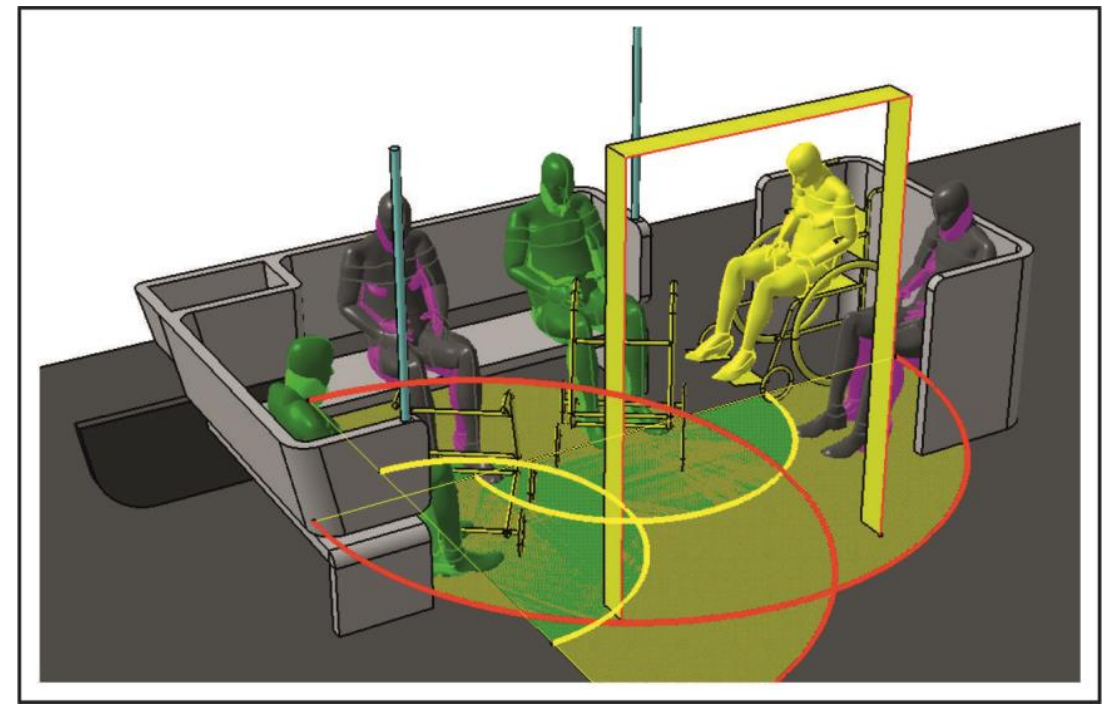

Fig. 6. Evaluation of a vehicle interior with personas and in the use case "Early evening" taking into account their usage behavior: Door accessibility for the user group "pensioner" is acceptable.

\subsection{Concept Evaluation with User-Scenarios}

By the application of the physically modelled personas and their combination to design-critical user-scenarios, the evaluation of the systematically generated vehicle 
package and the vehicle interior could be realized. Figure 6 shows an example of the evaluation of the vehicle interior with regard to the usage scenario 3 "Early evening".

In general, the positioning of the personas according to the specifications can be achieved with success. It becomes clear that the rollators clearly limit the available space in the interior. The positioning and orientation of the person with reduced mobility works. On the basis of the formulated requirements, the dimensional layout concept even provides space for two wheelchairs. The wheelchair user's entry or exit from the bus depends on the posture of the regular bus user or commuter shown in the figure in grey/magenta. If required, the regular bus user may need to arise from the folding seat to enable the transfer of the wheelchair user. The positioning of regular bus users or commuters as a function of the requirements is uncomplicated.

\section{Discussion and Conclusion}

This contribution shows the possibility of designing vehicles for public transportation with focus on the requirements of the passengers by applying the extended persona method, adapted to the vehicle's dimensional layout conception.

A comparison of the observation results of the real-life passengers with the fictional persona-based user scenarios showed a good match. It can be assumed that the defined user scenarios can also be observed at other locations and at different times of day. However, statements regarding transferability require further observations with alterations in the respective boundary conditions.

In this project, user scenarios were initially defined by combining personas and were subsequently evaluated with regard to their existence. It is probable that user scenarios defined on the basis of observations can more accurately reflect reality. Unfortunately, this procedure was not possible during the conduct of the course because the demand-responsive operating system was only implemented at a late stage of the project. However the project showed that this novel user-representation could be adequately implemented in a standardized overall vehicle design process.

It also showed that, the evaluation of a vehicle interior in consideration of designcritical user scenarios is not effortless. This means that the personas have to be positioned and oriented in the vehicle interior, by taking into account the defined specifications before an evaluation is carried out. This evaluation can than serve as a basis for modifications.

Similarly, the user scenarios can serve as a design basis. In this case, the positioning of persons and objects need to be clearly defined in the initial dimensional layout concept.

\section{Acknowledgments}

The described research activities were part of the collaborative project "Reallabor Schorndorf", funded by the German state of Baden Württemberg. Sincere thanks on behalf of the entire project consortium to the Ministry of Science, Research and Art of the German State of Baden-Württemberg (Fig. 7) for the funding of this project. 


\section{2) \\ Baden-Württemberg \\ WISSENSCHAFT FÜR NACHHALTIGKEIT}

MINISTERIUM FÜR WISSENSCHAFT, FORSCHUNG UND KUNST

Fig. 7. Sponsor of the presented collaborative project

\section{References}

1. Ministerium für Wissenschaft, Forschung und Kunst Baden-Württemberg (MWK): BadenWürttemberg fördert Reallabore. Internet 10. Januar 2019 (https://mwk.badenwuerttemberg.de/de/forschung/forschungspolitik/wissenschaft-fuernachhaltigkeit/reallabore/).

2. Der Spiegel: Kleine Grüne. In: Der Spiegel. Nr. 12/1981, S. 107-109, (http://www.spiegel.de/spiegel/print/d-14319388.html).

3. Helsinki Regional Transport Authority (HSL): Kutsuplus - Final Report. 2016 (https://www.hsl.fi/sites/default/files/uploads/8_2016_kutsuplus_finalreport_english.pdf).

4. gbk - Gütegemeinschaft Buskomfort e.V.: Kriterien zur Klassifizierung des RAL Gütezeichens Buskomfort. https://www.buskomfort.de/guetezeichen/kriterien.html, 28.09.2017.

5. Bubb, H., Bengler, K., Grünen, R. E. und Vollrath, M. (Hrsg.): Automobilergonomie, ATZ / MTZ Fachbuch. Wiesbaden: Springer Vieweg Verlag, 2015.

6. Schmid, S.; Maier, T.: Technisches Interfacedesign, Anforderungen, Bewertung und Gestaltung. Berlin: Springer Vieweg Verlag, 2017.

7. Baumann, K.: Personas as a user-centred design method for mobility-related services. Information Design Journal 18(2), 2010, P. 157-167.

8. Hörold, S., Kühn, R., Mayas, C. und Schlegel, T.: Interaktionspräferenzen für Personas im öffentlichen Personenverkehr. In: Eibl, M. (Hrsg.): Mensch \& Computer 2011: 11. fachübergreifende Konferenz für interaktive und kooperative Medien. überMEDIEN ÜBERmorgen, 11.-14.09.2011 Chemnitz, München: Oldenbourg Verlag, P. 367-370.

9. IP-KOM-ÖV: 07/08 2011 Der Nahverkehr. Publikation Projekt „Internet Protokoll basierte Kommunikationsdienste im Öffentlichen Verkehr“ (IP-KOM-ÖV), 2011.

10.Miaskiewicz, T. und Kozar, K. A.: Personas and user-centered design: How can personas benefit product design processes? Design Studies 32(5), 2011, P. 417-430.

11.Pruitt, J. S. und Adlin, T. (Hrsg.): The persona lifecycle: keeping people in mind throughout product design. Amsterdam: Elsevier, 2006.

12.VDI 2221. 1993-05. Methodik zum Entwickeln und Konstruieren technischer Systeme und Produkte

13.Klötzke, M., Brost, M., Fraedrich, E.-M., Gebhardt, L., Karnahl, K., Kopp, G., König, A., Müller, A., Sippel, T., Ulmer, F.: BOOLEAN - Ein haltestellenloses Quartiersbussystem für Schorndorf. mobilität - 9. Wissenschaftsforum 2017, Mobility and Digital Transformation Challenges and Future Paths, Duisburg, 2017.

14.Müller A., Kopp G., Beyer S., Deisser O. Nutzergerechte Fahrzeugentwicklung im ÖPNV mit erweiterter Persona-Methode. In: Piskun A. (eds) Karosseriebautage Hamburg 2018. Proceedings. Springer Vieweg, Wiesbaden, 2018.

15.Beyer S., Müller A.: Evaluation of Persona-Based User Scenarios in Vehicle Development. In: Ahram T., Karwowski W., Taiar R. (eds) Human Systems Engineering and Design. IHSED 2018. Advances in Intelligent Systems and Computing, vol 876. Springer, Cham, 2018. 